\title{
Human milk glycosaminoglycans inhibit in vitro the adhesion of Escherichia coli and Salmonella fyris to human intestinal cells
}

\author{
Giovanni V. Coppa', Bruna Facinelli², Gloria Magi², Emanuela Marini², Lucia Zampini', Veronica Mantovani ${ }^{3}$, Tiziana Galeazzi', \\ Lucia Padella', Rita L. Marchesiello', Lucia Santoro', Alessandra Coscia ${ }^{4}$, Chiara Peila ${ }^{4}$, Nicola Volpi ${ }^{3}$ and Orazio Gabrielli'
}

BACKGROUND: Breast-fed infants have a lower incidence of acute gastroenteritis due to the presence of several anti-infective factors in human milk. The aim of this work is to study the capacity of human milk glycosaminoglycans (GAGs) to inhibit the adhesion of some common pathogenic bacteria. METHODS: GAGs were isolated from a pool of milk samples collected from different mothers during the first month of lactation. Experiments were carried out to study the ability of GAGs to inhibit the adhesion of two intestinal micro-organisms (enteropathogenic Escherichia coli serotype 0119 and Salmonella fyris) to Caco-2 and Int-407 cell lines.

RESULTS: The study showed that the GAGs had an anti-adhesive effect on the two pathogenic strains studied with different degrees of inhibition. In particular, in the presence of human milk GAGs, the adhesion of S. fyris to Caco-2 cells and to Int-407 cells of both tested strains was significantly reduced.

CONCLUSION: Our results demonstrated that GAGs in human milk can be one of the important defensive factors against acute diarrheal infections in breast-fed infants.

$\mathrm{n}$ infancy, a wide variety of bacteria, viruses, and parasites are responsible for gastrointestinal infections. There is strong evidence to support the correlation between breastfeeding and a lower incidence of diarrhea. In fact, several anti-infective substances (secretory antibodies, lactoferrin, oligosaccharides, etc.) are present in human milk $(1,2)$. Oligosaccharides, in particular, play several important protective, physiological, and biological roles including growth stimulation for beneficial gut microbiota and inhibition of pathogen adhesion and immunoregulation $(3,4)$.

Glycosaminoglycans (GAGs) are highly sulfated, complex, linear natural polysaccharides constituted by repeating disaccharidic units. They are generally grouped into four classes: hyaluronan, keratan sulfate, sulfated galactosaminoglycans represented by chondroitin sulfate and dermatan sulfate bearing D-galactosamine, and sulfated glucosaminoglycans with heparan sulfate and heparin having D-glucosamine. Each specific disaccharidic unit is formed of a hexosamine (galactosamine or glucosamine) residue alternated with a hexuronic acid (glucuronic or iduronic acid) with the exception of keratan sulfate containing galactose. Sulfate groups are esterified on various positions of carbohydrate backbones producing structures possessing high heterogeneous sequences and charge density (5).

Contrary to oligosaccharides, GAGs are able to specifically (and aspecifically) interact with other biological components due to the presence of a great number of sulfate and carboxyl groups capable to generate highly specific sequences producing strong anionic interactions (5-7). As a consequence, it emerges that human milk GAGs could play a role as soluble receptors and would therefore have the power to inhibit the binding of different pathogens to the intestinal mucosa, thus protecting the infant from infections. Furthermore, human milk hyaluronan was recently demonstrated to stimulate protective antimicrobial defense in the newborn (8).

After the pioneering studies of Newburg et al. (9), a complete quantitative and qualitative evaluation of GAGs has recently been reported both in term and preterm human milk $(10,11)$. From the quantitative point of view, the highest concentration of GAGs was found in colostrum $(9.3$ and $3.8 \mathrm{~g} / \mathrm{l}$ in preterm and term milk, respectively), followed by a progressive decrease to 4.3 and $0.4 \mathrm{~g} / \mathrm{l}$ at the end of the first month of lactation. From these data, it follows that breast-fed newborns daily ingest consistent amounts of GAGs. From the qualitative point of view, chondroitin sulfate and heparan sulfate/heparin represent 55 and $42 \%$ of total GAGs, respectively, whereas dermatan sulfate and hyaluronan make up the remaining $3 \%$ (12).

Milk GAGs are synthesized in the mammary gland by the sequential action of specific glycosyltransferases, linked to a protein "core" and excreted as proteoglycans. At the small intestine level, the proteolytic enzymes secreted in the pancreatic juice digest the "core" of proteoglycans, liberating the GAG chains. As the intestinal wall and microvilli lack specific glycosidases and sulfatases, the free GAGs persist undegraded

\footnotetext{
'Pediatric Division, Department of Clinical Sciences, Polytechnic University of Marche, Ospedali Riuniti, Presidio Salesi, Ancona, Italy; ${ }^{2}$ Unit of Microbiology, Department of Biomedical Sciences and Public Health, Polytechnic University of Marche, Ancona, Italy; ${ }^{3}$ Department of Life Sciences, University of Modena and Reggio Emilia, Modena, Italy; ${ }^{4}$ Neonatal Unit, Department of Public Health and Pediatrics, University of Turin, Turin, Italy. Correspondence: Orazio Gabrielli (o.gabrielli@univpm.it) 


\section{Articles | coppa etal.}

in the upper part of the digestive system (13) where, behaving as soluble receptors, they could play an anti-infective role, as already demonstrated for human milk oligosaccharides (14).

The aim of this study is to verify whether the purified complex of human milk GAGs is able to inhibit the adhesion of two pathogen bacteria of diarrhea in infancy, such as Escherichia coli and Salmonella fyris (15) to Caco-2 and Int-407 cells.

\section{RESULTS}

Preliminary cell adhesion experiments demonstrated that both E. coli O119 and S. fyris were able to adhere to Caco-2 and Int-407 monolayers (data not shown). The Caco-2 and Int-407 cells' viabilities after incubation with GAGs dissolved at a concentration of $1.5 \mathrm{mg} / \mathrm{ml}$ were evaluated using the Trypan blue assay. In this test, only living cells are able to exclude the dye. After 1-h incubation, the cell viability of GAGs-treated monolayer was identical to that of the corresponding controls. In particular, the percent of viability of Caco-2 in presence of GAGs was $99.68 \pm 0.56 \%$ vs. control having $99.39 \pm 0.69 \%$ and that of Int -407 was $97.19 \pm 1.08 \%$ vs. control showing $96.32 \pm 0.95 \%$.

In agglutination assays performed with GAGs at the same concentration used in cell adhesion inhibition experiments, no agglutination of both E. coli O119 and S. fyris was detected. These results give us no possibility to measure any specific binding capacity between human milk GAGs and bacteria.

On the basis of these results, several adhesion experiments, performed in triplicate and repeated at least three times, were conducted by infecting Caco-2 and Int-407 cells with E. coli O119 and S. fyris, both in the presence of GAGs and in their absence. A significant reduction in the percentage of adhesion of S. fyris to Caco-2 cells and of E. coli O119 and S. fyris to Int-407 cells was observed in the presence of purified human milk GAGs complex dissolved at a concentration of $1.5 \mathrm{mg} / \mathrm{ml}$ (Figure 1). In particular, the percentage of adhesion of $S$. fyris to Caco-2 cells dropped from $7.7 \pm 1.2$ to $5.4 \pm 0.6(P=0.0412)$ (Figure 1a) whereas that of E. coli O119 and S. fyris to Int-407 cells dropped from $8.5 \pm 2.6$ to $2.1 \pm 1.0(P=0.0043)$ and from $32.1 \pm 5.5$ to $15.2 \pm 8.9(P=0.0112)$, respectively (Figure $1 \mathbf{b})$. The reduction of E. coli $\mathrm{O} 119$ adhesion to Int-407 monolayers in the presence of GAGs was also appreciable by Giemsa staining (Figure 2a,b). On the contrary, no effect of purified GAGs on E. coli O119 adhesion to Caco-2 monolayers was observed (Figures 1a and 2c,d).

\section{DISCUSSION}

Microbial infection is a complicated process largely dependent on the host-microbe relationship. Usually, adhesion is the first step leading to colonization and subsequent infection (16). Various cellular components on eukaryotic cells and tissues have been identified as targets for adhesion by micro-organisms, and many of them are characterized as proteoglycans. Recent studies have suggested that carbohydrate-containing molecules rather than proteins mediate bacterial attachment to the surface of eukaryotic cells (17). A considerable number of carbohydrate-binding specificities have been reported and, in some cases, the bacterial attachment to host animal cells has been linked directly to the interactions with GAGs $(18,19)$. The overall process of binding involves the meeting of a solvated polyhydroxylated glycan placed on the surface of cells with a solvated protein-combining site (adhesin) present on the pathogenic agent. The forces involved in this link are represented by hydrogen binding, Van der Walls interactions, and charge and dipole attraction $(20,21)$, suggesting that, if a surface on the glycan is complementary to the protein-combining site, water can be displaced and binding occurs.

Receptors present on the surface are made up of oligosaccharidic residues of glycoproteins and glycolipids of cell membranes. It has been proved that the adhesion to such receptors can be inhibited or reduced by the presence of free oligosaccharides with a structure analogous to that of cell receptors so that the pathogenic agent binds with them and not with the cell membrane, with a reduction of the pathogenic effect as a consequence (22).

Data available so far regarding the activity of human milk oligosaccharides toward E. coli and S. fyris show the capacity of fucosyl-oligosaccharides containing fractions to inhibit the adhesion of enteropathogenic E. coli O119. Moreover, the anti-adhesive effect on S. fyris, even though rather weak, was obtained by acid and neutral low-molecular-weight oligosaccharides (14).

As already demonstrated for other human milk (oligo)saccharides, exogenous GAGs have shown the ability as competitive inhibitors of bacterial adhesion, among which heparin has been studied most $(3,23)$. As concerns the possible physiological role of GAGs in the gastrointestinal tract of breast-fed newborns, it is important to underline that undigested GAGs reach the small intestine because there are no specific enzymes present on the intestinal wall able to degrade them. Therefore, these molecules could behave as soluble receptors having the power to interact with pathogens and to compete for their adhesion to the intestinal wall.

The present study confirms that GAGs are effective in inhibiting the adhesion of $S$. fyris to Caco-2 and Int-407 cells and adhesion of E. coli $\mathrm{O} 119$ to just Int-407. On the other hand, the presence of GAGs does not significantly inhibit the adhesion of E. coli O119 to Caco-2 cells. The adhesion values for S. fyris and E. coli $\mathrm{O} 119$ to Int-407 cells are concordant with those previously reported by comparing different configurations of cell cultures as an intestinal epithelium model (24). The adhesion percentages of these bacteria were reduced when the cell suspensions were co-incubated with GAGs, suggesting that GAGs may be involved in bacteria-epithelial cell interaction.

As concerns E. coli $\mathrm{O} 119$ and the lack of specific adhesion inhibition to Caco-2, such a phenomenon could be explained by the different molecular structures of the receptors belonging to the two cellular types. The human milk GAG pool might show areater similarity to the Int- 407 receptors than the GAGs located on Caco-2. Moreover, previous studies suggested that reduced adherence is due to lower levels of adherence proteins rather than to physical inhibition $(25,26)$. Finally, the different degree of the adhesion inhibition to Int-407 cells compared with Caco-2 cells could also reflect the origin (embryonic and 


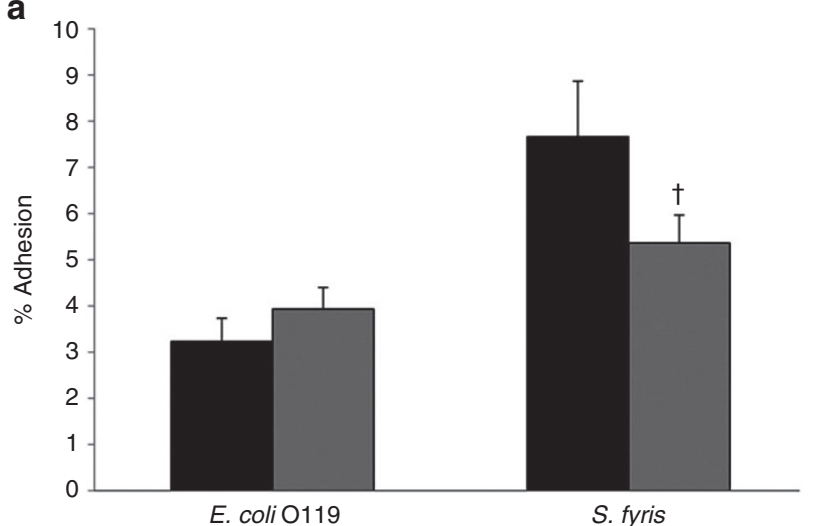

b

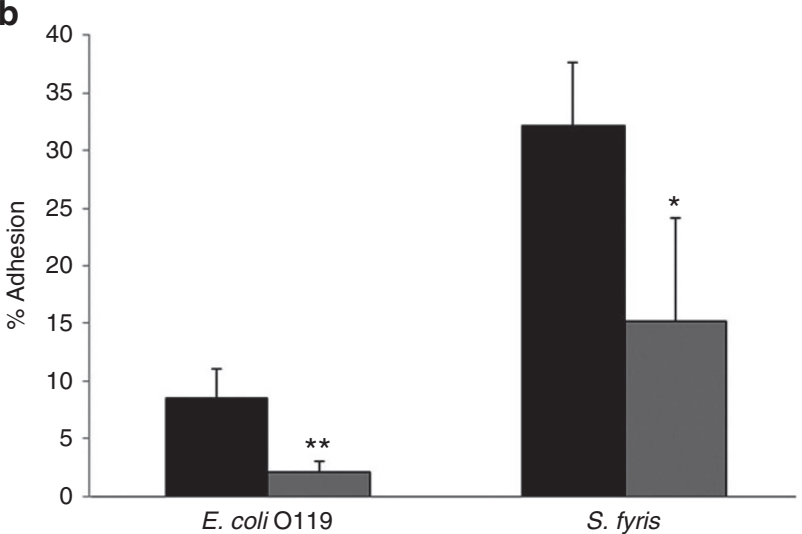

Figure 1. Inhibition of bacterial adhesion to intestinal cells by glycosaminoglycans (GAGs). Adhesion (percentage of the initial inoculum) of E. coli O119 and S. fyris (a) to Caco-2 and (b) to Int-407 cells in presence (gray bars) and absence (black bars) of GAGs. Values are expressed as mean \pm SD. Symbols on the figure denote statistically significant values compared with the control. ${ }^{*} P=0.0112 .{ }^{* *} P=0.0043 .{ }^{+} P=0.0412$.

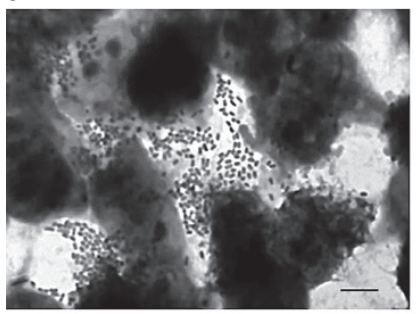

c

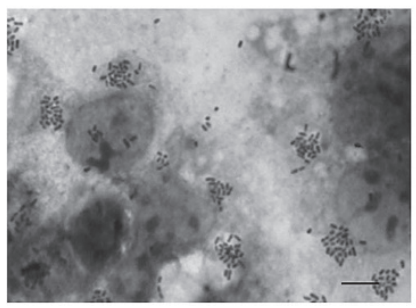

b

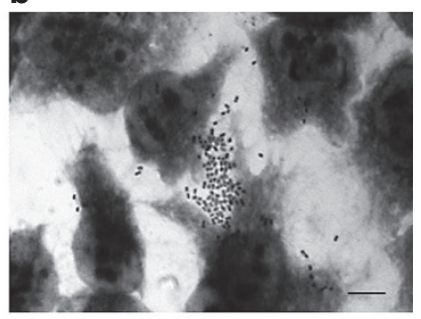

d

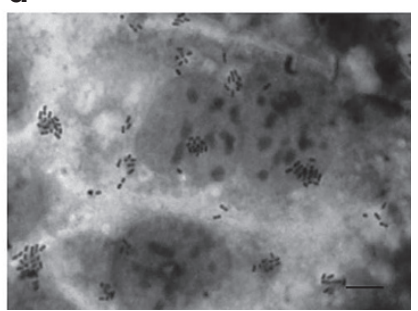

Figure 2. Standard light microscopy of Giemsa-stained cell monolayers infected with E. coli O119. Adhesion to Int-407 monolayers in the (a) absence and (b) presence of glycosaminoglycans (GAGs): a significant reduction in the adhesion of $E$. coli 0119 was observed in the presence of GAGs. Adhesion to Caco-2 monolayers in the (c) absence and (d) presence of GAGs: no effect of GAGs on E. coli O119 adhesion to Caco-2 monolayers was observed in the presence of GAGs. Magnification $=\times 1000$. Bar $=0.01 \mathrm{~mm}$.

adult, respectively) of the two cell lines. In fact, the human colon carcinoma cells Caco-2, widely used to study the adhesion of intestinal pathogens to human cells and cytotoxicity of enterobacteria, are physiologically closer to the natural targets of the pathogens as, in culture, they exhibit the differentiated features of enterocytes, such as cell polarity and apical brush border (27). On the other hand, Int-407, also used in adhesion experiments (28), are human embryonic intestinal cells having, as a consequence, possible different molecular structure(s) of receptor(s) compared with Caco- 2 .

The human milk GAGs tested are effective on the $S$. fyris and E. coli O119 though with different degrees of intensity. It has been shown that GAGs are also effective in inhibiting the HIV virus binding to the GP-120 receptor (9). Moreover, Hill et al.

(8) recently demonstrated that human milk hyaluronan inhibits the adhesion of S. typhimurium to cells. From the above results, it is derived that human milk GAGs have the capacity to act separately on different specific receptors. This effect may be related to their heterogeneous composition, structure, and properties of each single polysaccharide component. Our present results regarding the ability of human milk GAGs to inhibit the adhesion of enteropathogens to intestinal cells, as previously reported for human milk oligosaccharides, are a further demonstration that the anti-infective effect of human milk is the result of the presence of bioactive (macro)molecules able to protect newborns from the adhesion of some common pathogenic bacteria at gastrointestinal level.

On the basis of these results, further investigations will be performed using different GAG concentrations as well as single purified component present in human milk complex GAGs to better understand their possible physiological role and their involvement in the inhibition of bacteria adhesive mechanism.

\section{METHODS}

\section{GAGs Isolation}

Human milk GAGs were obtained from a pool of samples collected during the first month of lactation and stored at $-20{ }^{\circ} \mathrm{C}$ until use. Purified free GAGs were obtained and isolated as previously described in details (10). Briefly, single aliquots of human milk were defatted with acetone, and after centrifugation and drying at $60^{\circ} \mathrm{C}$, pellet was solubilized in adequate buffer and treated with a proteolytic enzyme. After boiling for $10 \mathrm{~min}$ and centrifugation, free GAGs were precipitated with three volumes of ethanol. The precipitate was recovered by centrifugation, dried at $60^{\circ} \mathrm{C}$ and purified on a column packed with anion-exchange resin. Column fractions positive to uronic acid assay (29) and containing free GAGs were collected and further precipitated with ethanol. Finally, after centrifugation and drying, the free purified complex human milk GAGs were analyzed for purity and composition and used for adhesion experiments.

The composition of purified GAGs was assessed by agarose-gel electrophoresis (30) and disaccharide determination after specific enzymatic treatment (10). The purity of the complex GAGs was greater than $85 \%$ as evaluated by uronic acid assay (29) with the remaining formed of salt and a very low content $(<1 \%)$ of proteins/ peptides. Human milk oligosaccharides were found absent due to the adopted protocol useful for the purification of GAGs, in particular the purification on strong-anion exchange resin and several precipitations with organic solvent (not shown). 


\section{Bacteria and Culture Conditions}

Two enterobacterial strains, both isolated from infants with diarrhea in Italy, were used: enteropathogenic E. coli ser. O119 (31) and Salmonella enterica subsp. enterica ser. Fyris (4,12:1, v,4,2 serotype), here named S. fyris. Both strains were previously used in inhibition studies with oligosaccharides (14). Enteropathogenic E. coli strains infect human populations throughout the world and remain one of the primary causes of acute infantile gastroenteritis in developing countries (32). In particular, enteropathogenic E. coli strains of the O119 serogroup have been found in association with infantile diarrhea in many countries (33). S. enterica subsp. enterica is an invasive, facultative intracellular pathogen of both animal and man with the ability to colonize various niches in diverse host organisms (34). The pathogenesis of infections by $S$. enterica subsp. enterica requires adhesion to cell surfaces, and a large number of adhesive structures can be found (35). Brain heart infusion (BHI) broth and agar (Difco Laboratories, Detroit, MI) were used for the routine growth of bacteria. Strains were maintained in glycerol at $-70{ }^{\circ} \mathrm{C}$ and subcultured twice before testing.

\section{Cell Lines}

The human colon carcinoma Caco-2 (ATCC HTB37) (36) and the human embryonic intestine Int-407 (ATCC CCL6) cell lines were used (37). Cells were routinely cultured in $50 \mathrm{ml}\left(25 \mathrm{~cm}^{2}\right)$ plastic tissue culture flasks (Corning Costar, Milan, Italy) in an atmosphere with 5\% $\mathrm{CO}_{2}$ at $37^{\circ} \mathrm{C}$ in Modified Eagle Medium (Gibco, Grand Island, New York) supplemented with $1 \%$ (v/v) L-glutamine (Gibco), 1\% (v/v) nonessential amino acids (Gibco), and 10\% (v/v) fetal calf serum (Gibco). Confluent cell monolayers were trypsinized and adjusted to a concentration of $2.5 \times 10^{5}$ cells $/ \mathrm{ml}$ in culture medium; $1-\mathrm{ml}$ cell suspension was dispensed into each $22-\mathrm{mm}$ well of a 12 -well tissue culture plate (Corning Costar) and incubated to obtain confluent monolayers.

The range of cell passage numbers used for the different experiments was 28-45 for Caco-2 cells and 312-320 for Int-407 cells.

\section{Determination of Cell Viability}

The effect of GAGs on Caco-2 and Int-407 monolayers was evaluated by using the Trypan blue exclusion assay able to give a measure of the cell viability (38). Briefly, Caco-2 and Int-407 monolayers were grown on SlideFlask and then incubated with GAGs dissolved at a concentration of $1.5 \mathrm{mg} / \mathrm{ml}$, as described earlier. Control cultures received culture medium without GAGs. At the end of 1-h infection period, the monolayers were washed, stained with $0.4 \%$ Trypan Blue solution (Gibco) at room temperature for $30 \mathrm{~min}$, and examined under light microscopy at $20 \times$ magnification. The viable cell ratio was calculated as follows: viable cell ratio $(\%)=$ (unstained cell number / total cell number $) \times 100$. Cell viability was determined as the percentage of the ratio of the number of unstained cells (viable) to the total number of unstained (viable) and stained (nonviable) cells.

\section{Agglutination Assay}

E. coli $\mathrm{O} 119$ and $S$. fyris strains were used in agglutination assays with GAGs, according to Facinelli et al. (39). Briefly, after overnight growth in $\mathrm{BHI}$ broth at $37^{\circ} \mathrm{C}$, bacterial cells were harvested and suspended in PBS to an optical density of $1.0 \pm 0.1$ at $540 \mathrm{~nm}$. Agglutination tests were carried out on sterile U-well microtiter plates (Greiner Labortechnik, Frickenhausen, Germany). In each well, $50 \mu \mathrm{l}$ of cell suspension was added to $50 \mu \mathrm{l}$ of GAGs dissolved at a concentration of $1.5 \mathrm{mg} / \mathrm{ml}$. As a control, $50 \mu \mathrm{l}$ of PBS was added to $50 \mu \mathrm{l}$ of GAGs and to $50 \mu \mathrm{l}$ of each cell suspension. Plates were incubated at $37{ }^{\circ} \mathrm{C}$ overnight and then visually inspected.

\section{Cell Adhesion Experiments}

Preliminary adhesion experiments were performed with two test strains at different incubation times on the basis of previously reported data (14). Briefly, after overnight growth at $37^{\circ} \mathrm{C}$ in BHI broth, bacterial cells were either subcultured in BHI broth and incubated in a shaker at $37{ }^{\circ} \mathrm{C}$ for $2 \mathrm{~h}$ (S. fyris) and then harvested by centrifugation at $5,000 \mathrm{rpm}$ or were directly harvested by centrifugation (E. coli O119). Bacterial cells were resuspended in PBS to $\mathrm{OD}_{540} 0.6 \pm 0.02$, diluted in Modified Eagle Medium, and added $(0.5 \mathrm{ml}$, approximately $1 \times 10^{8} \mathrm{CFU} / \mathrm{ml}$ ) to confluent monolayers. After incubation for $90 \mathrm{~min}$ (E. coli) or $120 \mathrm{~min}\left(\right.$ S. fyris) at $37^{\circ} \mathrm{C}$ in $5 \% \mathrm{CO}_{2}$, cells were washed three times with PBS to remove nonadherent bacteria and then lysed in Triton X-100 ( $0.1 \%$ in cold sterile water) to release adherent bacteria. CFU of bacteria were counted by plating suitable dilutions of the lysates on BHI agar and incubating for $36-48 \mathrm{~h}$ at $37^{\circ} \mathrm{C}$. Results were expressed as percentages of the initial inoculum. Adhesion experiments were performed in triplicate and repeated at least three times.

\section{E. coli 0119 and S. fyris Adhesion to Cell Monolayers in the Presence of GAGs}

Adhesion experiments were performed by assessing the rate of recovery of adherent bacteria from infected Caco- 2 or Int- 407 cells in the presence of GAGs. Briefly, after washing, monolayers were covered with $250 \mu \mathrm{l}$ of Modified Eagle Medium containing GAGs dissolved at a concentration of $1.5 \mathrm{mg} / \mathrm{ml}$ and incubated for $1 \mathrm{~h}$ at $37^{\circ} \mathrm{C}$ in $5 \%$ $\mathrm{CO}_{2}$. At the end of the incubation period, $250 \mu \mathrm{l}$ of bacterial inoculum (approximately $2 \times 10^{8} \mathrm{CFU} / \mathrm{ml}$ ) were added. After incubation at 37 ${ }^{\circ} \mathrm{C}$ in $5 \% \mathrm{CO}_{2}$, cells were washed three times with PBS, and adherent bacteria were recovered as described earlier. Results were expressed as percentages of the initial inoculum. Adhesion experiments were performed in triplicate and repeated at least three times.

Bacteria associated with Int- 407 and Caco-2 monolayers were also evaluated by Giemsa staining. Stained monolayers grown on slides (SlideFlask, Nunc GmbH, Weisbaden, Germany) were examined microscopically (Leica DMRB microscope, Wetzlar, Germany) using the $\times 100$ oil-immersion objective.

\section{Statistical Analysis and Ethical Approval}

Each cell adhesion assay was performed in triplicate and repeated at least three times. All data are presented as mean \pm SD. Significant differences between analyzed groups, i.e., cell adhesion in the absence and presence of GAGs, were calculated with the paired Student's $t$ test by using GraphPad software. $P$ values less than 0.05 were considered statistically significant.

The study protocol was approved by the ethics committee of the Italian Association of Human Milk Donor Banks.

\section{STATEMENT OF FINANCIAL SUPPORT}

The research has been partially supported by the Fondazione Mancini (Fabriano, Italy).

Disclosure: The authors declared no conflict of interest.

\section{REFERENCES}

1. Hamosh M. Bioactive factors in human milk. Pediatr Clin North Am 2001;48:69-86.

2. Morrow AL, Ruiz-Palacios GM, Jiang X, Newburg DS. Human-milk glycans that inhibit pathogen binding protect breast-feeding infants against infectious diarrhea. J Nutr 2005;135:1304-7.

3. Newburg DS. Neonatal protection by an innate immune system of human milk consisting of oligosaccharides and glycans. J Anim Sci 2009;87:13 Suppl:26-34.

4. Lane JA, Mehra RK, Carrington SD, Hickey RM. The food glycome: a source of protection against pathogen colonization in the gastrointestinal tract. Int J Food Microbiol 2010;142:1-13.

5. Jackson RL, Busch SJ, Cardin AD. Glycosaminoglycans: molecular properties, protein interactions, and role in physiological processes. Physiol Rev 1991;71:481-539.

6. Gesslbauer B, Theuer M, Schweiger D, Adage T, Kungl AJ. New targets for glycosaminoglycans and glycosaminoglycans as novel targets. Expert Rev Proteomics 2013;10:77-95.

7. Gandhi NS, Mancera RL. Heparin/heparan sulphate-based drugs. Drug Discov Today 2010;15:1058-69.

8. Hill DR, Rho HK, Kessler SP, et al. Human milk hyaluronan enhances innate defense of the intestinal epithelium. J Biol Chem 2013;288: 29090-104.

9. Newburg DS, Linhardt RJ, Ampofo SA, Yolken RH. Human milk glycosaminoglycans inhibit HIV glycoprotein gp120 binding to its host cell CD4 receptor. J Nutr 1995;125:419-24.

10. Coppa GV, Gabrielli O, Buzzega D, et al. Composition and structure elucidation of human milk glycosaminoglycans. Glycobiology 2011;21: 295-303. 
11. Coppa GV, Gabrielli O, Zampini L, et al. Glycosaminoglycan content in term and preterm milk during the first month of lactation. Neonatology 2012;101:74-6.

12. Coppa GV, Gabrielli O, Bertino E, et al. Human milk glycosaminoglycans: the state of the art and future perspectives. Ital J Pediatr 2013;39:2.

13. Roughley PJ, Mort JS. Catabolism of proteoglycans. In: Iozzo RV, ed. Proteoglycans: Structure, Biology and Molecular Interactions. New York: Marcel Dekker, 2000:93-113.

14. Coppa GV, Zampini L, Galeazzi T, et al. Human milk oligosaccharides inhibit the adhesion to Caco-2 cells of diarrheal pathogens: Escherichia coli, Vibrio cholerae, and Salmonella fyris. Pediatr Res 2006;59:377-82.

15. Lanata CF, Fischer-Walker CL, Olascoaga AC, Torres CX, Aryee MJ, Black RE; Child Health Epidemiology Reference Group of the World Health Organization and UNICEF. Global causes of diarrheal disease mortality in children $<5$ years of age: a systematic review. PLoS One 2013;8:e72788.

16. Sava IG, Zhang F, Toma I, et al. Novel interactions of glycosaminoglycans and bacterial glycolipids mediate binding of enterococci to human cells. J Biol Chem 2009;284:18194-201.

17. Imberty A, Varrot A. Microbial recognition of human cell surface glycoconjugates. Curr Opin Struct Biol 2008;18:567-76.

18. Henry-Stanley MJ, Hess DJ, Erlandsen SL, Wells CL. Ability of the heparan sulfate proteoglycan syndecan-1 to participate in bacterial translocation across the intestinal epithelial barrier. Shock 2005;24:571-6.

19. Hafez MM, Aboulwafa MM, Yassien MA, Hassouna NA. Role of different classes of mammalian cell surface molecules in adherence of coagulase positive and coagulase negative staphylococci. J Basic Microbiol 2008;48:353-62.

20. Lemieux RU. How water provides the impetus for molecular recognition in aqueous solution. Acc Chem 1996;29:373-80.

21. Esko JD, Linhardt RJ. Proteins that bind sulfated glycosaminoglycans. In: Varki A, Cummings RD, Esko JD, et al, eds. Essentials of Glycobiology. 2nd edition. New York: CSH Press, 2009:229-48.

22. Zopf D, Roth S. Oligosaccharide anti-infective agents. Lancet 1996;347:1017-21.

23. Hanson LA. Session 1: feeding and infant development breast-feeding and immune function. Proc Nutr Soc 2007;66:384-96.

24. Laparra JM, Sanz Y. Comparison of in vitro models to study bacterial adhesion to the intestinal epithelium. Lett Appl Microbiol 2009;49:695-701.

25. Knutton S, Adu-Bobie J, Bain C, Phillips AD, Dougan G, Frankel G. Down regulation of intimin expression during attaching and effacing enteropathogenic Escherichia coli adhesion. Infect Immun 1997;65:1644-52.
26. Vanmaele RP, Heerze LD, Armstrong GD. Role of lactosyl glycan sequences in inhibiting enteropathogenic Escherichia coli attachment. Infect Immun 1999;67:3302-7.

27. Rigothier MC, Coconnier MH, Servin AL, Gayral P. A new in vitro model of Entamoeba histolytica adhesion, using the human colon carcinoma cell line Caco-2: scanning electron microscopic study. Infect Immun 1991;59:4142-6.

28. Kusters JG, Mulders-Kremers GA, van Doornik CE, van der Zeijst BA. Effects of multiplicity of infection, bacterial protein synthesis, and growth phase on adhesion to and invasion of human cell lines by Salmonella typhimurium. Infect Immun 1993;61:5013-20.

29. Cesaretti M, Luppi E, Maccari F, et al. A 96-well assay for uronic acid carbazole reaction. Carbohydr Polymers 2003;54:59-61.

30. Volpi N, Maccari F. Detection of submicrogram quantities of glycosaminoglycans on agarose gels by sequential staining with toluidine blue and Stains-All. Electrophoresis 2002;23:4060-6.

31. Caprioli A, Pezzella C, Morelli R, et al. Enteropathogens associated with childhood diarrhea in Italy. The Italian Study Group on Gastrointestinal Infections. Pediatr Infect Dis J 1996;15:876-83.

32. Ochoa TJ, Contreras CA. Enteropathogenic Escherichia coli infection in children. Curr Opin Infect Dis 2011;24:478-83.

33. Gonçalves AG, Campos LC, Gomes TA, et al. Virulence properties and clonal structures of strains of Escherichia coli O119 serotypes. Infect Immun 1997;65:2034-40.

34. Giannella RA. Salmonella. In: Baron S, ed. Medical Microbiology. 4th edition. Galveston, TX: University of Texas Medical Branch at Galveston, 1996:571-84.

35. Wagner C, Hensel M. Adhesive mechanisms of Salmonella enterica. Adv Exp Med Biol 2011;715:17-34.

36. Rousset M. The human colon carcinoma cell lines HT-29 and Caco-2: two in vitro models for the study of intestinal differentiation. Biochimie 1986;68:1035-40.

37. Monteville MR, Yoon JE, Konkel ME. Maximal adherence and invasion of INT 407 cells by Campylobacter jejuni requires the CadF outer-membrane protein and microfilament reorganization. Microbiology 2003;149: 153-65.

38. Facinelli B, Giovanetti E, Magi G, Biavasco F, Varaldo PE. Lectin reactivity and virulence among strains of Listeria monocytogenes determined in vitro using the enterocyte-like cell line Caco-2. Microbiology 1998;144:109-18.

39. Facinelli B, Giovanetti E, Casolari C, Varaldo PE. Interactions with lectins and agglutination profiles of clinical, food, and environmental isolates of Listeria. J Clin Microbiol 1994;32:2929-35. 